\title{
STEROIDOGENESIS IN THE PREIMPLANTATION RAT EMBRYO AND ITS POSSIBLE INFLUENCE ON MORULA-BLASTOCYST TRANSFORMATION AND IMPLANTATION
}

\author{
Z. DICKMANN AND SUDHANSU K. DEY \\ Department of Gynecology and Obstetrics, University of Kansas Medical Center, \\ Kansas City, Kansas 66103, U.S.A.
}

(Received 12th Fuly 1973)

In the rat, two key reproductive phenomena-morula to blastocyst transformation, and implantation-are known to be affected by oestrogen/progesterone changes in the mother. Thus, experimentally imposed hormonal changes can prevent the transformation of morula to blastocyst (Dickmann, 1970,1973) and delay and induce implantation (Nutting \& Meyer, 1963; Mayer 1963). It has been axiomatic that the ovary is the source of oestrogen and progesterone necessary during the preimplantation period. The results of the present study suggest that the preimplantation embryo is an additional, perhaps indispensable, source of steroid hormones which influence the two phenomena mentioned.

Adult virgin female rats of the Holtzman strain, weighing 180 to $220 \mathrm{~g}$, were mated with males of proven fertility. The morning of finding spermatozoa in the vagina was designated Day 1 of pregnancy. On Days 3,4 and 5, rats were killed and the fertilized eggs were recovered according to the method described by Dickmann (1971), but instead of transfer medium, cold $\left(0\right.$ to $\left.5^{\circ} \mathrm{C}\right) 0.1 \mathrm{M}$ phosphate buffer ( $\mathrm{pH} 7.5$ ) was used to flush the eggs from the reproductive tract. The activity of $\Delta^{5}-3 \beta$-hydroxysteroid dehydrogenase $(3 \beta-\mathrm{OH}-\mathrm{SDH})$ in the eggs was determined histochemically. The eggs from each rat were transferred to $0.5 \mathrm{ml}$ incubation medium, the composition of which was: $1.8 \mathrm{mg}$ dehydroepiandrosterone (DHA), $4.0 \mathrm{mg}$ nicotinamide adenine dinucleotide (NAD), $2 \mathrm{mg}$ Nitro-Blue Tetrazolium (Nitro-BT), $0.4 \mathrm{mg}$ propylene glycol (the same results were obtained when dimethyl formamide was substituted for propylene glycol), and 9.6 ml 0.1 M-phosphate buffer ( $\mathrm{pH} \mathrm{7.5).} \mathrm{The} \mathrm{DHA} \mathrm{was}$ first dissolved in $0.25 \mathrm{ml}$ acetone which was later removed by evaporation. This is the same histochemical procedure as that described by Deane, Rubin, Driks, Lobel \& Leipsner (1962) except for minor modifications. The eggs were incubated at $37^{\circ} \mathrm{C}$ for $3 \mathrm{hr}$, but were briefly checked under a dissecting microscope every $30 \mathrm{~min}$ to record changes in formazan deposition, when it occurred. Following the 3-hr incubation period, the eggs were mounted in a small drop of incubation medium between a glass slide and a coverslip supported by four dots of a vaseline-paraffin mixture, and were examined under a compound microscope. A positive formazan reaction indicates $3 \beta-\mathrm{OH}-\mathrm{SDH}$ activity which in turn indicates synthesis of steroid hormones (Dorfman \& Ungar, 
1965; Wiest \& Kidwell, 1969). The intensity of the formazan reaction was scored as follows: negative, borderline positive reaction \pm , and four ascending grades of positive reactions,,,++++++++++ .

Seven pregnant rats were killed on Day 3 at 08.00 hours. They yielded fifty-four eggs (forty-six 2-cell, two 3-cell, five 4-cell and one 5-cell), none of which showed $3 \beta$-OH-SDH activity. Six rats were killed on Day 4 at 08.00 hours. They yielded sixty-eight eggs (eighteen 4-cell and fifty 8-cell), twentynine $(42.7 \%)$ of which showed $3 \beta$-OH-SDH activity. In four of twenty-nine eggs, all the blastomeres were positive whereas in the remaining twenty-five eggs, only some of the blastomeres were positive (Pl. 1, Fig. 1). Thus, the twenty-nine eggs (five 4-cell and twenty-four 8-cell) had a total of 212 blastomeres of which ninety-six $(45 \%)$ were positive. The intensities of the reaction in these blastomeres were as follows: thirty-six $(37 \cdot 5 \%) \pm$, fifty-three $(55 \cdot 2 \%)$ + , and seven $(7 \cdot 3 \%)++$. Six rats were killed on Day 4 at 16.00 hours. They yielded fifty-three eggs (three 4-cell and fifty 8 -cell), thirty-three $(62 \cdot 3 \%$ ) of which showed $3 \beta-\mathrm{OH}-\mathrm{SDH}$ activity, a considerable increase over the morning Day-4 eggs. In two eggs, all the blastomeres were positive, whereas in the remaining thirty-one only a fraction of the blastomeres were positive. The thirtythree eggs had a total of 264 blastomeres of which $116(44 \%)$ were positive. The intensities of the reaction in these blastomeres were: forty-four $(37.9 \%) \pm$, forty-five $(38.8 \%)+$, and twenty-seven $(23.3 \%)++$. Six rats were killed on Day 5 at 08.00 hours. They yielded fifty-four blastocysts, all exhibiting $3 \beta$ $\mathrm{OH}-\mathrm{SDH}$ activity. The activity occurred throughout each blastocyst, i.e. it was not confined to a fraction of an egg as seen in most Day-4 eggs (Pl. 1, Fig. 2). The intensities of the reaction in the blastocysts were: eight $(14.8 \%) \pm$, eighteen $(33.3 \%)+$, eighteen $(33.3 \%)++$, and ten $(18.5 \%)+++$. Six rats were killed on Day 5 at 16.00 hours. They yielded forty-nine zona-free blastocysts, all showing $3 \beta-\mathrm{OH}-\mathrm{SDH}$ activity which was seen throughout each blastocyst. The intensities of the reaction in the blastocysts were: four $(8.1 \%) \pm$, twelve $(24.5 \%)+$, fifteen $(30 \cdot 6 \%)++$, sixteen $(32 \cdot 7 \%)+++$, and two $(4 \cdot 3 \%)++++$.

In all cases, positive reactions were confined to the blastomeres, i.e. there were no formazan granules in either the perivitelline space, the zona pellucida, or in the supernumerary spermatozoa when present (in about $20 \%$ of the eggs).

Concurrently with the above experiments, blastocysts and morulae were incubated in DHA-free medium (control); the reaction was negative in all cases. A few eggs recovered on Days 4 and 5 had degenerated; in all of them, the reaction was negative.

Since $3 \beta-\mathrm{OH}-\mathrm{SDH}$ activity in a tissue indicates steroid hormone synthesis, we suggest that the preimplantation embryo synthesizes steroid hormones. If so, this permits us to construct the two following hypotheses. (1) Transformation of morula to blastocyst depends, at least in part, on stimulation of steroid hormones produced by the morula. This hypothesis is consistent with the findings that (a) transformation of morulae occurs in hormone-free media in vitro (shown by several authors, particularly in the mouse), (b) morulae develop into blastocysts subsequent to their transfer into the uteri of long-term ovariectomized rats (Dickmann, 1969), and (c) the transformation of morulae is blocked in pregnant rats whose oestrogen/progesterone balance is experi- 


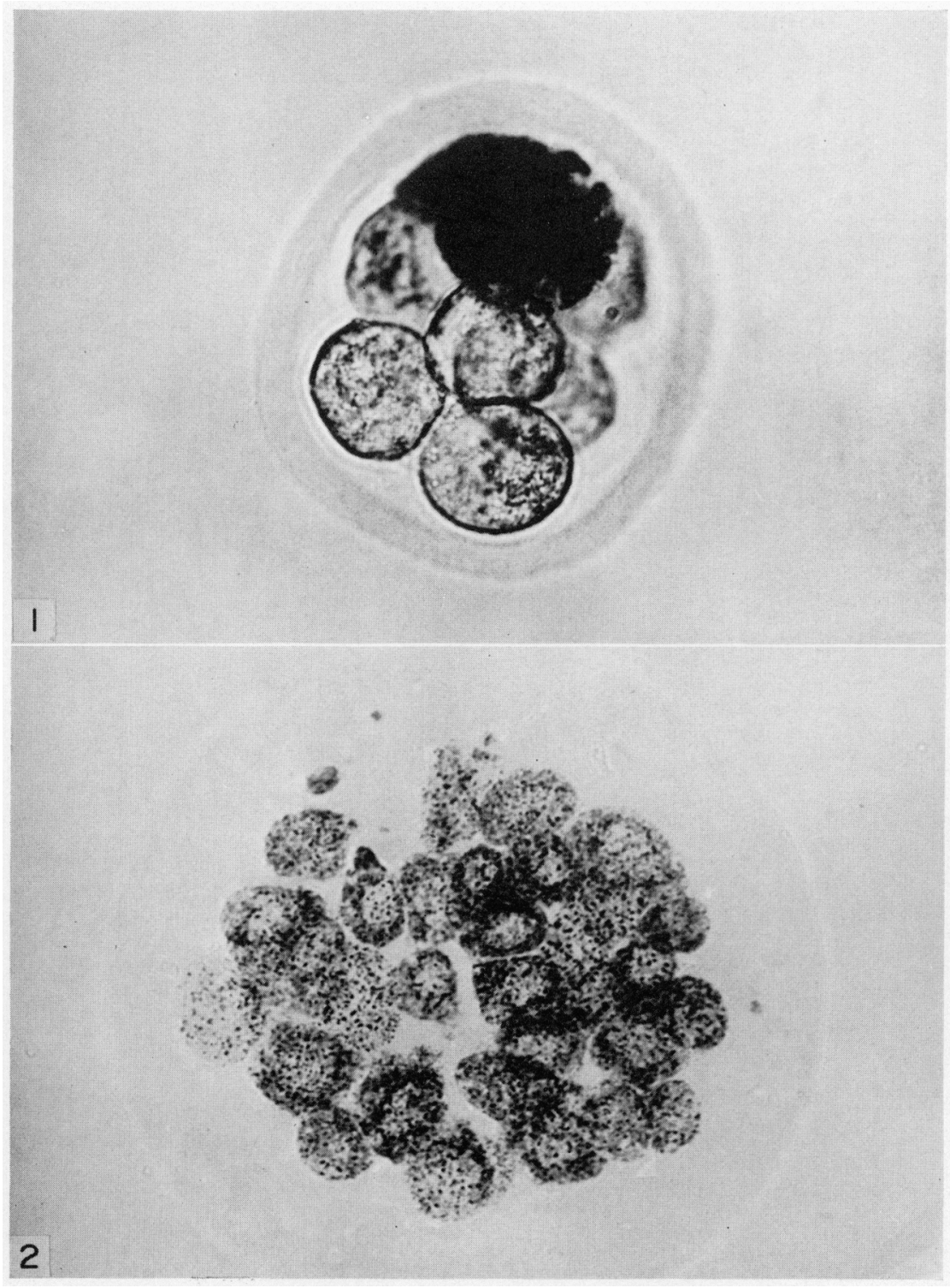

Fig. 1. Morula recovered at 08.00 hours on Day 4 of pregnancy. Two of eight blastomeres are $3 \beta$-OH-SDH positive. $\times 545$.

Fig. 2. Blastocyst recovered at 08.00 hours on Day 5. The blastocyst, which had been flattened under the coverslip, shows formazan granules in all the blastomeres. $\times 545$.

(Facing p. 92) 
mentally disturbed (Dickmann 1970, 1973). An interpretation for the latter results, not previously given, is that the treatments caused oestrogen/progesterone imbalance within the morula which, in turn, prevented transformation. (2) After the embryo settles on a prospective site for implantation, it exerts a local hormonal effect on the endometrium which is critical for implantation. Implantation begins late in the afternoon of Day 5 . The $3 \beta-\mathrm{OH}-\mathrm{SDH}$ activity was first observed 30 to $26 \mathrm{hr}$ earlier, and it then increased. This is a time relationship suggestive of preimplantation hormonal conditioning. In other words, the two sources of steroid hormones, the ovary and the preimplantation embryo, complement each other and implantation cannot occur in the absence of either source.

At present, it is not known whether preimplantation embryos of mammals other than the rat have steroidogenic capability. We feel that such a capability will be demonstrable in most mammals. If so, some enigmas which have confronted the student of implantation could be explained on the basis of hormone secretion by the preimplantation embryo. Two examples may be cited. (a) Orsini \& Meyer (1959) have shown that in the hamster, progesterone stimulation by itself is sufficient to prime the uterus for implantation. By contrast, in rat and mouse, progesterone and oestrogen are required. It could be postulated that the apparent hormone-lack in the hamster is made up by the embryo. (b) Implantation occurs in guinea-pigs ovariectomized several days earlier and not given any hormonal therapy (Loeb \& Hesselberg, 1917; Deanesly 1960); again, the hormones required may be provided by the embryos.

This study was supported in part by a Population Council grant to Z.D. and S.K.D. is a post-doctoral Ford Foundation fellow.

\section{REFERENCES}

Deane, H. W., Rubin, B. L., Driks, E. C., Lobel, B. L. \& Leipsner, G. (1962) Trophoblast giant cells in placentas of rats and mice and their probable role in steroid-hormone production. Endocrinology, 70, 407.

DeanzsLy, R. (1960) Implantation and early pregnancy in ovariectomized guinea-pigs. f. Reprod. Fert. 1, 242.

Dickmann, Z. (1969) Hormonal requirements for the transformation of morula to blastocyst in the rat: effects of long-term ovariectomy. Steroids, 14, 385.

Dickmann, Z. (1970) Effects of progesterone on the development of the rat morula. Fert. Steril. 21, 541.

Dickmann, Z. (1971) Egg transfer. In Methods in Mammalian Embryology, p. 133. Ed. J. C. Daniel, Jr. W. H. Freeman \& Company, San Francisco.

Dickmann, Z. (1973) Postcoital contraceptive effects of medroxyprogesterone acetate and oestrone in rats. 7. Reprod. Fert. 32, 65.

Dorfman, R. I. \& Ungar, F. (1965) Metabolism of Steroid Hormones. Academic Press, New York.

Loeb, L. \& HesselberG, C. (1917) The cyclic changes in the mammary gland under normal and pathological conditions. Part III. J. exp. Med. 25, 305.

MAYER, G. (1963) Delayed nidation in rats: a method of exploring the mechanism of ova-implantation. In Delayed Implantation, p. 213. Ed. A. C. Enders. University of Chicago Press.

Nutring, E. F. \& MEYeR, R. K. (1963) Implantation delay, nidation, and embryonal survival in rats treated with ovarian hormones. In Delayed Implantation, p. 233. Ed. A. C. Enders. University of Chicago Press.

Orsini, M. W. \& Meyer, R. K. (1959) Implantation of the castrate hamster in the absence of exogenous estrogen. Anat. Rec. 134, 619 .

WIEST, W. G. \& KIDWELL, W. R. (1969) The regulation of progesterone secretion by ovarian hydrogenases. In The Gonads, p. 295. Ed. K. W. McKerns. Appleton-Century-Crofts, New York. 